Canadian Journal of Family and Youth, 2(1), 2009, pp 1-23

ISSN 1718-9748@OUniversity of Alberta

http://ejournals.library.ualberta.ca/index/php/cjfy

\title{
Undue Influence as a Family Affair
}

\author{
Bonnie Lashewicz, Norah Keating, and Jack Phelan
}

\begin{abstract}
Siblings sharing responsibility for parent care, and entitlement to parent assets, are sometimes dissatisfied with how their parents' estates are distributed following a period of care to the parent. Such dissatisfaction can be advanced through legal claims by some siblings that other siblings, during the course of giving care, exerted undue influence over the parent to obtain their assets. The Canadian legal doctrine of undue influence directs attention to what transpired between two parties in the interest of protecting vulnerable people from having to honor arrangements to which they did not truly consent. In these cases, the focus is on the relationship between a sibling as an adult child, and the now deceased care recipient parent. At the same time, these cases reflect expectations and dynamics among siblings relative to each other. In this paper, a family, rather than dyadic, perspective is employed to illuminate elements of undue influence claims that are relevant to the sibling experience of giving care and sharing assets. We thus expand on understandings of dyadic issues addressed by the courts.
\end{abstract}

\section{Introduction}

The law has a tradition of applying the equity doctrine of undue influence to protect vulnerable parties from the sway of more powerful entities. As the legal profession responds to the needs of an aging population in Canada, greater attention may be directed to the potential vulnerability of seniors who have age associated needs for support. One such area of recent interest involves parents receiving care from adult children and using assets to compensate these children for their caregiving. In some of

\footnotetext{
Bonnie Lashewicz, Assistant Professor, Department of Community Health Sciences, University of Calgary, Norah Keating, Professor, Department of Human Ecology, University of Alberta and Jack Phelan teaches in the Faculty of Health and Community Studies, Grant MacEwan University, Edmonton. Correspondance on this article should be directed to Bonnie Lashewicz at bmlashew@ucalgary.ca.
} 
these cases, one or more siblings of a caregiver make legal claims that the caregiver exerted undue influence to obtain parent assets. The law's response focuses on what transpired between the caregiving sibling and the care receiving parent in an attempt to determine and honour the true intentions of the parent. Yet by studying these claims more broadly, in terms of family rather than dyadic relationships, it becomes evident that not only are the interests of the potentially vulnerable parent at stake, but also the interests of siblings relative to each other.

In claims of undue influence, the focus is on the person alleged to have been unduly influenced. The behavior of the person who would benefit is presented only for how it constitutes evidence that the other person experienced undue influence and typically relates to actions that contributed to the other person becoming dependent on the person who would benefit. In the case of a care receiving parent living with an adult child for example, evidence may be presented that the caregiving child did not allow the parent access to a telephone thereby leaving the parent with limited outside communication and corresponding dependence on the caregiving child. Additional elements of undue influence are evident in sibling claims as the behavior of the sibling who would benefit is also portrayed as having restricted or prevented other siblings from having input into parent affairs. Thus with the example above, not only was the parent's freedom for outside communication restricted, but also other siblings freedom to interact with their parent. While ties between parent and child are central as the courts judge how much the parent was influenced by a particular child, ties between siblings are also prominent as siblings compare themselves in relation to having influence over the aging parent. The purpose of this paper is to examine how siblings compare their involvement 
in parent care and asset distribution decisions and illuminate how ties between siblings can be operative in claims that one sibling unduly influenced a parent. The analysis provided in this paper will contribute to our ability to judge claims of undue influence in light of multiple family relationship dynamics.

\section{Siblings and their Aging Parents: A Theoretical Overview}

Population aging in developed countries has resulted in increasing concern about care needs of growing cohorts of older adults. Adult children are central to the discourse about how these needs are and will be met. The "emotional and biological bond between parent and child gives the relationship a permanent and central place in our lives quite apart from whether that relationship turns out well or poorly" (Callahan, 1985, p. 35). According to Callahan, all children experience the centrality of this relationship and a corresponding sense of caregiving responsibility. This sense of "filial" responsibility has been discussed as some combination of love, duty and a desire to reciprocate for their upbringing (Aronson, 1990) and used to capture why adult children provide care to aging parents (Gans \& Silverstein, 2006; Globerman, 1995; Lewinter, 2003; Ohta \& Kai, 2007). The essence of filial responsibility was demonstrated in Globerman's findings that, although siblings within families behaved differently in relation to the care needs of their aging parents, all had a sense of ownership for caregiving.

Siblings spend a lifetime developing separate identities from equivalent locations in the family lineage. From a young age, siblings experience a strong sense of identification inherent to their equivalent status as well as a strong need for differentiation from each other (Apter, 2007; Sulloway, 1996). An emerging literature provides insights into how adult sibling identities may be reasserted as parents near the 
Lashewicz, Keating, and Phelan

end of their lives (Cicirelli, 1995; Lashewicz \& Keating, 2009). Their genealogical equivalence means that structurally, siblings have similar levels of caregiving obligation. Similarities in level of obligation are exemplified in research findings that siblings expect to share parent care responsibilities and tasks (Connidis, 2001; Ingersoll-Dayton, Neal, Ha, \& Hammer, 2003).

Siblings have been found to act "in concert" in responding to the needs of parents. When "siblings started providing assistance, the odds of an adult child initiating assistance were greater" (Dwyer, Henretta, Coward, \& Barton, 1992, p. 372). Caregiving entails a sense of responsibility not only to the older person, but also to other family members. Thus, a sibling may provide care to a parent not simply to meet the needs of the parent, but also to alleviate other siblings' concerns with meeting the parent's needs (Cicirelli, 1995; Donorfio \& Kellett, 2006; Piercy, 1998). Siblings may work in complementary and coordinated fashion determining their own care contributions partly based on what other siblings are contributing (Checkovich \& Stern, 2002; Duner \& Nordstrom, 2007).

Siblings are keenly aware of their shared responsibility for parent care and judge the adequacy of each other's contributions (Lashewicz, Manning, Hall \& Keating, 2007). Parent care can be a site for tensions among siblings when some are viewed as insufficiently contributing to parent care (Harris, 1998; Ingersoll-Dayton, Neal, Ha \& Hammer, 2003). Most documented cases of sibling concern over the adequacy of each other's caregiving centre on perceptions that some siblings are not doing their share. However, tensions among siblings can occur because some siblings are regarded as having too great an influence in care. For example, in families where one sibling resides 
with an aging parent in need of care, other siblings may be troubled over having to submit to decisions made by their co-resident caregiving sibling (Cicirelli, 1995). Similarly, siblings have expressed dissatisfaction at what they describe as other siblings excluding them by maintaining control over decisions pertaining to parents (George, 1986; Lashewicz \& Keating, 2009). Their genealogically equivalent status seems to leave siblings alert to the importance of sharing responsibility so that everyone is doing enough without any particular sibling being overly influential.

Although siblings may have similar levels of parent care obligation and consider it important that their influence in parent care decisions is shared, their care contributions are not usually even. An array of personal factors including personality, gender, other family responsibilities, employment status, and proximity to the care recipient, drives the type and extent of sibling involvement (Ingersoll-Dayton et al., 2003). Siblings take personal factors into account and may conclude that other siblings are shirking responsibilities with only "flimsy excuses" (Merrill, 1997). Alternatively, siblings' lesser contributions to parent care may be judged more charitably by other siblings if these are seen as justified by “legitimate excuses” (Finch \& Mason, 1993).

Receiving property from a parent can serve as a caregiving motive. In a study of farm families, Heenan (2000) concludes that, as a result of inheriting the family business, adult children feel obligated to provide care. A connection between property and care is also evident in findings that children who received support from parents in their adult lives are more likely to provide parent care (Silverstein, Conroy, Wang, Giarusso \& Bengston, 2002). At the same time, some work indicates that having received parent resources in the past is associated with a reduced likelihood of providing care (Pezzin \& 
Lashewicz, Keating, and Phelan

Schone, 2001). Such findings may relate to work showing that parents give resources to children considered to be less independent (Hall, 2002b). It may be that resource receiving children are less prepared to provide care than other children in the family. Yet other work has been aimed at considering sibling dynamics in the context of parent care and property transfer. White-Means \& Hong (2001) found that competition exists between siblings and concluded that adult children are more likely to provide time and money to help their parents if they have siblings, the presence of whom was interpreted by adult children as competition for bequests.

While evidence about whether receiving property is a motive for giving care may be mixed, siblings seem consistently attentive to what each does and receives. In some families, care agreements are made to address imbalances in caregiving by giving greater shares of parent assets to siblings viewed by the care recipient parents as making greater care contributions (Hall, 2002b). Agreements are usually motivated by a parent's desire to continue residing in the family home in the face of declining independence. A parent may also be seeking companionship and wishing to avoid being cared for by strangers. Additionally, offering property for care is a way for a parent to provide for an adult child (Hall, 2002b). Care agreements represent a departure from typical sibling expectations for sharing equally in parent assets (Finch, Hayes, Mason, Masson, \& Wallis, 1996) and have been subject to legal dispute among siblings on variety of grounds including claims that a caregiving sibling obtained parent assets by exerting undue influence.

\section{Conceptual Approach and Methods}


Sibling relationships are important to how people approach issues related to their aging parents. Yet little is known about sibling dynamics amidst the intense circumstances raised by equal obligations to provide parent care combined with equal entitlement to parent assets. To illuminate sibling relationships by examining how siblings compare their involvement in parent care and asset distribution decisions, we draw upon the choice and exchange theory assumption that people evaluate their situations in terms of costs and rewards and through comparisons with the situations of others (Sabetelli \& Shehan, 1993). Imbalances in one's costs and rewards compared with costs and rewards of others' are expected to lead to distress in the form of resentment at being underbenefitted and guilt at being overbenefitted (Walster, Walster \& Berscheid, 1978; White \& Klien, 2002). Moreover, evaluations of costs and benefits are multifaceted, deriving from personal standards related to where a particular cost or benefit is placed in an individual's "hierarchy of values" (Nye, 1979). Siblings raised in a common home environment are expected to share values; at the same time, siblings' unique social characteristics, experiences and interpretations are expected to lead to differences in values (Apter, 2007; Silverstein, Conroy \& Gans, 2008). By examining standards siblings use to evaluate and compare their care contributions and asset entitlements, we illuminate ways in which similarities and differences in values are brought to bear on sibling claims that other siblings unduly influenced a parent.

To focus this examination of standards of evaluation, we use concepts from the literature on family caregiving that have been found important to how siblings determine their involvement in parent care and compare their own involvement to that of other siblings (Lashewicz \& Keating, 2009). Sibling views are studied for how these entail 
comparisons in terms of concepts of filial responsibility, genealogical equivalence and the relevance of personal factors. Applying this combination of concepts enabled us to capture some of the dynamic character of family relationships as we were able to focus not only on how siblings experienced their own sense of responsibility to their aging parents, but also how they perceived their responsibility to have played out relative to others with equivalent status and responsibility. In addition, we draw on the legal concept of care agreement, which involves a transfer of parent assets in exchange for parent care (Hall, 2002a), to narrow our focus to include an examination of how using assets to compensate caregiving can influence sibling comparisons of their respective involvements in parent affairs.

To illuminate relationship dynamics among sibling caregivers and add to understandings of how undue influence is experienced in families, we gathered sibling perspectives from two distinct sources of data. Legal case portrayals of sibling claims that other siblings had, during the provision of care, exerted undue influence to obtain parent assets were collected. Legal cases tend to be concisely focused representations compiled by judges to provide the facts of the case of how one sibling allegedly exerted undue sway over a parent followed by the judge's ruling on the case and justification for the ruling. A second source of data was collected through in-depth interviews with siblings facing issues of giving parent care and receiving parent assets but not (or not yet) pursuing legal action over perceived unfairness. Interview data provided more detailed, conversational accounts of a range of sibling relationships relative to aging parents including situations characterized by conflict and situations where there was no indication of conflict. Building on the narrative tradition that stories provide access to 
the richness of experience (Rosenblatt, 2001), our two data sources offer stories told in two distinct styles to two different audiences and were brought together in the interest of obtaining a more complete picture of relationships among caregiving siblings.

We examined three Canadian legal cases that portray claims by some siblings that others, during the provision of parent care, exerted undue influence. These three cases are part of a broader sample of eighteen cases which represent all cases in Canada initiated between 1995 and 2004 depicting sibling disputes over parent assets in relation to parent care. The three cases were selected from the eighteen because they are specifically about undue influence claims and succinctly represent the key themes of how sibling interests can be prevalent in undue influence claims which we identified in the broader sample. In analyzing disputes specific to some sibling's concerns that others dominated decisions about the aging parent, we show how sibling relationships can be focal to the ways in which the interests of the parent are presented in legal proceedings. The time frame was limited in the interest of reflecting contemporary families. Given our focus on sibling ties, cases included were about disputes between siblings who share two biological parents. One case from each of Alberta (1997), Prince Edward Island (2003) and British Columbia (1997) are included. Legal case documents are numbered by paragraph (II) rather than page. Because the cases are part of public record, real names are used in reporting and referencing this data.

To expand on and detail the range of sibling relationships studied, we conducted in-depth interviews with eleven siblings from eight care giving families. Family groups with two or more siblings were recruited through a long-term care center, a wills and estates lawyer and a senior's newsletter. In the aim of gaining as full a sibling 
perspective as possible, a reasonable effort was taken to interview as many siblings from each family as were available and would agree to participate. Siblings were asked questions about how they acted as part of a sibling group in relation to decisions about giving parent care and receiving parent assets, whether the distribution of care and assets was fair, and the bases on which fairness was evaluated. While in the legal cases, asset distribution was focal, in the interviews, caregiving was central with asset distribution questions asked in relation to care that was being or had been given. Siblings interviewed described care and asset sharing situations ranging from harmonious to intensely conflicted. Sibling responses were tape recorded and transcribed. When interview data are presented, pseudonyms are assigned to siblings.

A content analysis of the legal case documents and interview transcripts was done using the choice and exchange theory concept of comparison along with caregiving concepts of filial responsibility, genealogical equivalence and relevance of personal factors, as well as the legal concept of care agreements. Data were examined for how siblings as responsible equals compared their respective levels and types of influence in decisions concerning their aging parent including when assets were exchanged for care.

\section{Results}

Siblings sense of their equivalence and accompanying expectations for equal opportunity for influence in matters of parent care and parent asset distribution were evident in the data. Siblings in the legal cases were distressed if they perceived their own involvement in their parents' care and asset decisions to have been prevented or restricted by their siblings; they viewed such situations as having implications for how parent assets 
were distributed. Siblings described having their opportunities for influence prevented when other siblings acted without consultation. Siblings described having their opportunities for influence restricted when other siblings withheld information or restricted communication with the parent.

\section{Opportunities for Influence Prevented: Lack of Consultation}

Siblings described how other siblings made and acted upon decisions without consultation. The legal case of the Coughlan Estate (2003) profiles a dispute between two sisters. While at different times both sisters had provided live-in care to their father, Mary, the sister who had most recently given live-in care, was the sole recipient of her father's estate. Her sister, Frances, disputed the distribution of the estate claiming that Mary had made and acted upon decisions without consulting her. Frances noted that Mary had at one point removed their father from his long-term care center without anyone's knowledge. Mary countered that removing him was what their father wanted. Nonetheless, when Mary took him from the center, she told the staff at the center that she was merely taking him out for a drive. Frances maintained that she was left without an opportunity for input into decisions because Mary had acted in secret.

A similar lack of consultation was evident in the Henry family based on an interview with Victor, one of six siblings. Victor described how ensuring their mother had adequate nutrition was cause for much debate and disagreement within his sibling group. For over a year, Victor had been preparing and packaging a daily meal for his mother which he delivered once or twice a week. Victor also made telephone calls daily to ask his mother what she was having for dinner, thus confirming that she was eating the meals. Victor's sister Paula, allied with their sister Karen, disagreed with Victor about 
Lashewicz, Keating, and Phelan

meal provision. Paula had contended that Victor's meals went against her belief that their mother needed "to learn to do things for herself." As their mother's dementia progressed and her need for care became more pronounced, Paula conceded that meal provision was appropriate, but told Victor, "Your meals are not nutritious." Finally, furthering her position that the meals were not satisfactory, Paula, without Victor's knowledge, set up a formal "Meals on Wheels" service despite the fact that Victor continued to provide meals.

For her part, Paula claimed that Victor failed to consult with her and instead individually controlled decisions about their mother's care needs as well as about what was to happen to their mother's house once their mother entered long term care. In a group email to her siblings, shared by Victor during his interview, Paula called Victor "the one with the power" whose "opinion seems to be the only one that counts." Victor countered saying his style is gentle and responsive to his mother's needs, a key reason their father had designated Victor, rather than his more controlling sister Paula, to be their mother's power of attorney. Victor said their father knew he would listen to their mother whereas Paula would do what Paula wants, “come Hell or high water". Paula maintained that it was Victor who is controlling and undemocratic. In a later email, Paula remarked: "I guess when you have a dictator in the family, there isn't much anyone can do." In another email she noted that, "It seems that Victor is calling the shots, and it's either his way or the highway."

A lack of consultation was also evident in the Baker family based on an interview with Linda, one of two sisters. During her interview, Linda shared a letter from her sister Joan who complained about Linda's single-handedness in selling their parents' home. 
Regarding Linda's decision to sell, Joan claimed "Big sister spoke. . . . It was your way or the highway, right?" At another point in their correspondence about where their parents would live following the sale of their house, Joan called Linda "Big Shiska", a slang term for "one in charge". Further strife between these two sisters was evident as each claimed the other had acted without consultation regarding their mother's wish to move from a temporary apartment back to living in her house. Linda agreed with her mother and made arrangements for the move to occur. On the day of the move, Joan arrived hurriedly with her family and had the move reversed. Joan literally "intercepted them, forced them to put everything back into Mother's apartment."

A lack of consultation left some siblings without opportunity to influence parent decisions and, in a number of cases, resulted in a tug of war style struggle for influence. Providing evidence of a style contrasting with this type of struggle, Barb, who was interviewed from the Ellingham family of seven siblings, spoke of her satisfaction with the consultative style of decision making among her siblings. She noted that she and two of her sisters were particularly coordinated with each assuming different care tasks - one focused on their mother's meals, another on their mother's medical appointments and the third on their mother's leisure interests - and would regularly "compare notes and ideas" in planning their steps for supporting their mother to continue to live in her own home.

\section{Opportunities for Influence Restricted: Information Withheld}

Claims that information was withheld were voiced in the legal case of Tracy v. Boles (1996) where two siblings who lived at a distance, Katherine and Arthur, disputed the majority of their father's estate being left to their caregiving sister, Doris, who lived near their father. Katherine and Arthur described what they viewed as information 
withholding on the part of Doris. For example, Katherine and Arthur pointed out that some of their father's property that each of them had received, officially came from Doris rather than from their father. Doris noted that during her caregiving, she had made plans with her father for him to join her and her husband in moving from Nova Scotia to British Columbia and planning for this move involved their father transferring his assets to Doris for her to use for the relocation. However, Katherine and Arthur were surprised that the property they eventually received came under Doris' name. Further, Katherine and Arthur expressed distress specifically at not having been told that the property was in Doris's name even though they had been together as a family at their mother's funeral one month after their father's property had been transferred to Doris.

Paula from the Henry family where one brother, Victor, was interviewed, also contended that her sibling had withheld information. Specifically, Paula felt ill informed of the results of her mother's residential placement assessments that had been overseen by Victor. At one point in an email to her sibling group, Paula chastised Victor: "You're supposed to share information!" At another point Paula claimed that she felt left out of decisions and claimed that Victor was not giving her "the information I deserve and need."

Reinforcing the idea that siblings become distressed when information is not shared, Carol, one of two siblings interviewed from the Gordon family of four siblings, demonstrated the benefits of an open sharing of information among siblings as she noted that while she and two of her siblings had lived at a distance from their mother and visited periodically, her sister Beth, who had provided live-in care to their mother for ten 
Undue Influence as a Family Affair

years, consistently enabled coordinated planning by being "very good at keeping us informed."

\section{Opportunities for Influence Restricted: Parent-Child Communication Limited}

Siblings felt restricted in their opportunities for influence in their parents' affairs as they described their communication with their parent as having been limited by their siblings. Katherine and Arthur from the legal case of Tracy v. Boles (1996) contended that their sister Doris had dominated their father in part by limiting his communication with them. Katherine and Arthur pointed out that while Doris lived in the apartment suite adjacent to the father's suite, she "had connected his doorbell to a bell in her suite" (ף 46). Katherine also indicated that Doris insisted on being present during Katherine's visits with their father. Doris countered with the claim that her presence was important during visits from Katherine in order that Doris be available to help their father respond to Katherine's questions about the plans Doris and their father had made to move from Eastern to Western Canada.

A claim of having communication with a parent restricted by siblings was advanced in the legal case of Shannon v. McCullough (1997) where three of five siblings, Danny, Noreen, and Barbara, contested the distribution of their mother's estate that favored the children of another sibling, Suzanne. Suzanne had provided live-in care to their mother on and off for several years and the three siblings who contested the will submitted that Suzanne had influenced their mother's decisions in part by limiting their mother's communication with the other siblings. Danny, Noreen and Barbara claimed that because Suzanne had such close contact with their mother, including acting as their 
mother's liaison, that Suzanne had created distance between their mother and the other three siblings.

In the legal case of the Coughlan Estate (2003) Mary contended that her communication with her father was restricted by her sister Frances. Mary said Frances had tried to isolate and dominate their father when he lived with Frances. Mary's claim was supported by her brother's testimony that Frances was a "forceful" person. Specific sibling restrictions on communication between a parent and other siblings were evident when "Bennet says he tried to have a phone put in his father's room, but Frances wouldn't allow it” ( $($ 36).

By contrast, Barb, who was interviewed from the Ellingham family of seven siblings, illustrated the value of siblings being careful to avoid interfering with each other's communication and involvement with a parent. Barb expressed that she and her siblings were satisfied with their respective involvement and spoke of her own role in supporting their mother as entailing working around her siblings' contributions. Barb organized her involvement to be "a comfortable place to do my thing with Mom one-onone without interfering or stepping on toes."

Siblings made the most positive evaluations of their relationships relative to their aging parents when they considered themselves to have equal opportunity for influence. Jim, who was interviewed from the Frank family of three siblings, gave an example of the evenness of opportunity among himself and his siblings as he noted that if an emergency arose in relation to his mother, the long term care center where his mother lived would contact whichever sibling they could reach first: "There's no priority there." 


\section{Discussion}

Transfers of assistance between generations, such as giving care to a senior parent, or giving assets to a caregiving child, are "nested in a complex network of related individuals that compose the family system" (Silverstein, 2006, p. 166). Yet much of our knowledge about family care has been developed by studying the experience of individual caregivers in relation to care recipients. On the surface, this practice of focusing on individual experiences relative to one other family member is mirrored in legal cases as these are concentrated on the experience of an individual who was unduly influenced by another family member. The findings presented here expand our view to encompass more of the family system by demonstrating that when a sibling claims another sibling exerted undue influence over an aging parent, the experience of the parent relative to one adult child is only part of what is relevant. As well as thinking about whether their parent truly consented to an arrangement, siblings are concerned with their own position within a sibling network, and their opportunity for influence as members of this network. These concerns with opportunities as members of a sibling network are also evident among siblings interviewed who share responsibility for parent care and entitlement to parent assets.

As well as illuminating broader family dynamics surrounding undue influence claims, the current findings provide insight into sibling relationships in adult life. While considerable work has been done to understand rivalry among siblings during childhood and adolescence, much less work has been focused on adult siblings. Some scholars conclude that compared to other family relationships, adult sibling relationships are 
Lashewicz, Keating, and Phelan

weakly regulated by social norms and patterns of closeness and contact among siblings vary widely depending on sibling interests and compatibility (Apter, 2007; Conley, 2004). A parent's need for care and planning for distribution of assets may spark a resurgence of sibling contact and identity. Identification as a sibling group is clear in our data as siblings feel responsible for aging parents and expect to have comparable influence in decisions about parent care and assets. Within group differentiation is also evident in the form of siblings' differing involvement in parent affairs as well as in sibling references to distinctions according to gender or birth order that privilege certain siblings in decision-making.

In the current data, when decisions were perceived as being made between a parent and one or more particular sibling, others were distressed. Indeed, in looking across legal and interview sources, the most positive evaluations of sib relationships relative to aging parents occurred among siblings who consider themselves equally influential in parent affairs to the extent that their efforts are virtually indistinguishable as evident in the case where in an emergency, the long term care facility would call whichever sibling they could reach first. Perhaps the Ellingham family represents an ideal as these siblings work closely together yet distinguish between their distinct contributions in positive ways such as by being careful not to interfere with each other's individual efforts. Contrastingly, dramatic claims of dissatisfaction arise in situations where siblings act as the sole influence in the parent's affairs through actions such as relocating a parent without the knowledge of other siblings or failing to share important information. 
These findings of sibling expectations for equal influence in parent care and asset decisions may cast filial responsibility in a different light. Filial responsibility has been construed as entailing obligations to provide assistance and care when required by parents. The current findings of sibling dissatisfaction over other siblings' dominating influence hold potential to challenge images of caregiving as obligation and instead, portray caregiving as something in which siblings feel entitled to participate. The analysis may position legal practitioners to more fully understand family dynamics operative on parties presenting on one side or the other of undue influence allegations. Beliefs that undue influence occurred stem from a sibling's perception that the involvement of other in parent care entailed lack of consultation, withholding information, or limiting their communication with their parent.

Thus although legal claims are of undue influence of a caregiver on a parent, family tensions are about equity in sibling relationships. Siblings calculated fairness by comparing their caregiving inputs and rewards. Some siblings were viewed as reaping greater rewards by blocking caregiving input of others and thus positioning themselves to receive disproportionate amounts of parent assets. From our cross-sectional data, unanswered questions remain about whether these disagreements over parent care and asset distribution reflect a continuation or intensification of longstanding sibling differences.

In addressing undue influence problems that siblings encounter in these scenarios, the legal system must, to an extent, make decisions based on whose "storyline" or view of fairness is more compelling. Perhaps the Family Court and the Child, Youth and Family Enhancement Act in Alberta (Revised Statutes of Alberta 2000, Chapter C-12), 
which is focused on the protection of children, might provide a framework for continued thinking about legal decision making in response to the types of disputes profiled in this study. Under this act, children are viewed as vulnerable and in need of protection. At the same time, the act is broadly aimed at supporting the functioning of families. The issues identified in the current study dramatically impact family functioning. Although adults are legally viewed as capable of protecting themselves, perhaps when an adult asks for assistance in the form of "care", even if this is forthcoming from family members, this adult could be seen as falling into the category of needing protection. Issues such as undue influence, which manifest in sibling behaviors such as restricting information and making decisions without consultation, are categories which the court might consider in terms of both a need for protection of the older adult and an assertion of the siblings' right to be involved. Perhaps siblings' genealogically equivalent status could be viewed as creating an equal right to decision making in the "custody" of a parent not unlike the rights shared by parents in relation to their children.

Under what circumstances might formal care agreements prevent or alleviate sibling disputes over undue influence? Care agreements are useful because they allow scrutiny of these sibling relationships and of the potential for undue influence on frail older parents. They will be most successful when siblings have established a collaborative style of caregiving, comparing notes and ideas and keeping one another informed. Care agreements most likely will be challenged in cases such as those reported here in which siblings believe that their equal status has not brought them equal rewards of property and influence. From the perspective of families facing decisions about supporting a frail parent, care agreements can be seen as symbols of inequity or vehicles 
to reward unequal but fair parental caregiving. Regardless, the opportunity for open discussion of the disposition of parent assets can help illuminate tensions or collaboration in caregiving families.

\section{References}

Apter, T. (2007). The sister knot: Why we fight, why we're jealous, and why we'll love each other no matter what. New York: W. W. Norton \& Company.

Aronson, J. (1990). Old women's experiences of needing care: Choice or compulsion? Canadian Journal on Aging, 9(3), 234-247.

Callahan, D. (1985). What do children owe elderly parents? Hastings Center Report, 15(2), 32-37.

Checkovich, T. \& Stern, S. (2002). Shared caregiving responsibilities of adult siblings with elderly parents. The Journal of Human Resources, XXXVII (3), 441-78.

Cicirelli, V.G. (1995). Sibling relationships across the life span. New York: Plenum Press.

Conley, D. (2004). The pecking order: Which siblings succeed and why. New York: Random House.

Connidis, I.A. (2001). Family ties and aging. Thousand Oaks, CA: Sage.

Coughlan Estate, Re. (2003). Prince Edward Island Supreme Court. Retrieved May 29, 2004, from the LawSource database at http://ecarswell.westlaw.com

Donorfio, L.K.M., \& Kellett, K. (2006). Filial responsibility and transitions involved: A qualitative exploration of caregiving daughters and frail mothers. Journal of Adult Development, 13(3/4): 158-167.

Duner, A., \& Nordstrom, M. (2007). The roles and functions of the informal support networks of older people who receive formal support: A Swedish qualitative study. Ageing \& Society, 27 (1), 67-85.

Dwyer, J., Henretta, J., Coward, R., \& Barton, A. (1992). Changes in the helping behaviors of adult children as caregivers. Research on Aging, 14(3), 351-375.

Finch, J., \& Mason, J. (1993). Negotiating family responsibilities. London: Routledge.

Finch, J., Hayes, L., Mason, J., Masson, J., \& Wallis, L. (1996). Wills, inheritance, and 
families. Oxford, UK: Clarendon Press.

Gans, D.S., \& Silverstein, M. (2006). Norms of filial responsibility for aging parents across time and generations. Journal of Marriage \& Family, 68(4): 961-976.

George, L. (1986). Caregiver burden: Conflict between norms of reciprocity and solidarity. In K.A Pillemer \& R. S. Wolf (Eds.), Elder abuse: Conflict in the family (pp. 67-92). Dover, MZ: Auburn House.

Globerman, J. (1995). The unencumbered child: Family reputations and responsibilities in the care of relatives with Alzheimer's Disease. Family Processes, 34, 87-99.

Hall, M. I. (2002a). Private care agreements between older adults and friends or family members (BCLI Rep. No. 18). Vancouver, BC: University of British Columbia, British Columbia Law Institute.

Hall, M. I. (2002b). The care agreement: Transfer of property in exchange for the promise of care and support. Estates, Trusts, \& Pensions Journal, 21, 210-276.

Harris, P. (1998). Listening to caregiving sons: Misunderstood realities. The Gerontologist, 38(3), 342-352.

Heenan, D. (2000). Expectations and attitudes affecting patterns of informal care in farming families in Northern Ireland. Ageing and Society, 20, 203-216.

Ingersoll-Dayton, B., Neal, M.B., Ha, J.H., \& Hammer, L.B. (2003). Redressing inequity in parent care among siblings. Journal of Marriage and Family, 65(1), 201213.

Kaur Estate v. Bhandar (1996). British Columbia Supreme Court. Retrieved March 2, 2004, from www.courts.gov.bc.ca.

Lashewicz, B., Manning, G., Hall, M., Keating, N. (2007). Equity matters: Doing fairness in the context of family caregiving. Canadian Journal on Aging, 26 (suppl 1), 91102.

Lashewicz, B. \& Keating, N. (2009). Tensions among siblings in parent care. European Journal of Ageing, 6, 127-135.

Merrill, D.M. (1997). Caring for elderly parents: Juggling work, family, and caregiving in middle and working class families. Westport, CT: Auburn House.

Nye, F. I. (1979). Choice, exchange, and the family. In W.R. Burr, R. Hill, F. I. Nye, \& I. L. Reiss (Eds.), Contemporary theories about the family: General theories/Theoretical orientations (pp. 1-41). New York: The Free Press.

Ohta M., \& Kai, I. (2007). The cross-validity of the filial obligation scale. Archives of Gerontology \& Geriatrics, 45(1): 1-8. 
Pezzin, L. E. \& Schone, B. (2001). The allocation of resources in intergenerational households: Adult children and their elderly parents. Women, Health and Aging, 87 (2), 460-4.

Piercy, K. W. (1998). Theorizing about family caregiving: The role of responsibility. Journal of Marriage and the Family, 60, 109-118.

Rosenblatt, P. C. (2001). Qualitative research as a spiritual experience. In K. R. Gilbert (Ed.), The emotional nature of qualitative research (pp. 111-128). Boca Raton, FL: CRC Press.

Sabatelli, R. M., \& Shehan, C. L. (1993). Exchange and resource theories. In P. G. Boss, W. J. Doherty, R. LaRossa, W. R. Schrumm, \& S. K. Steinmetz (Eds.), Sourcebook of family theories and methods: A contextual approach (pp. 385-417). New York: Plenum Press.

Shannon v. McCullough (1997). Alberta Court of Queen's Bench. Retrieved May 20, 2004, from the Quicklaw database at http://www.lexisnexis.ca

Silverstein, M. (2006). Intergenerational Family Transfers in Social Context. In R. Binstock \& L. George (Eds.), Handbook of Aging and the Social Sciences $\left(6^{\text {th }}\right.$ ed.) (pp. 166-176). Burlington, MA: Elsevier Inc.

Silverstein, M., Conroy, S. \& Gans, D. (2008). Commitment to caring: Filial responsibility and the allocation of support by adult children to older mothers. In M. E. Szinovacz \& A. Davey (Eds.), Caregiving contexts: Cultural, familial and societal implications. (pp. 71-91). New York: Springer.

Silverstein, M., Conroy, S., Wang, H., Giarusso, R., \& Bengston, V. (2002). Reciprocity in parent-child relationships in American families. American Journal of Sociology, 103, 429-460.

Simpson v. Simpson (1997). British Columbia Supreme Court. Retrieved June 1, 2004, from the LawSource database http://ecarswell.westlaw.com

Sulloway, F. (1996). Born to rebel: Birth order, family dynamics, and creative lives. New York: Random House.

Tracy v. Boles (1996). British Columbia Supreme Court. Retrieved March 2, 2004, from http://www.courts.gov.bc.ca.

Walster, A. J., Walster, G. W., \& Berscheid, E. (1978). Equity: Theory and research. Boston: Allyn and Bacon.

White-Means, S. I., \& Hong, G. S. (2001). Giving incentives of adult children who care for disabled parents. The Journal of Consumer Affairs, 35(2), 364-389. 